\title{
Exploration on the Construction of Online and Offline Blending Teaching Mode in the Introduction to Earth Science
}

\author{
Xiehui Li* \\ School of Atmospheric Sciences, Chengdu University of Information Technology, Chengdu, Sichuan, 610225, China
}

\section{ARTICLE INFO}

Article history

Received: 1 October 2021

Revised: 8 October 2021

Accepted: 15 October 2021

Published Online: 30 October 2021

\section{Keywords:}

Online and offline

Blending teaching

Introduction to earth science

Construction of teaching mode

\begin{abstract}
The course "Introduction to earth science" is a basic general course integrating science and interest run by the School of Atmospheric Sciences in Chengdu University of Information Technology. It is also a public elective course for the cultivation of college students' scientific quality. With the development of Internet plus education and the promotion of information technology, the paper combines the traditional offline teaching mode with the online teaching mode adopted during the spring semester in 2020 because of the COVID-19, giving full play to the advantages of the two teaching modes. According to the school's teaching environment and teaching objectives, the online and offline blending teaching mode is constructed by introducing the recording of course video + MOOC + SPOC + online resources of high-quality open courses + Flipped Classroom + Rain Classroom + QQ group + WeChat + Tencent meeting, in order to improve the comprehensive teaching performance, and provide an important reference for the educational reform of similar courses in the post epidemic era.
\end{abstract}

\section{Introduction}

The Internet, which appeared in the twentieth century, has not been developing for a long time, but its development speed is amazing. With the rapid development of computer and Internet, the era of the "Internet plus" has made the online learning popular all over the world. In the early spring of 2020, influenced by the COVID-19, all primary and secondary schools in China delay the spring semester in order to prevent the epidemic spreading in the campus. At the same time, the Ministry of Education requires all schools to ensure the "classes suspended but learning and teaching continue" and "online and offline teaching qualities are equivalent" in the "guidance on the organization and management of online teaching in colleges and universities during the epidemic prevention and control period" ${ }^{[1]}$. Under this severe situation, colleges and universities have made full use of various modern information techniques to realize online teaching, which not only brings great challenges and new development opportunities, but also promotes the construction and reform of online teaching platforms and resources. In the fall semester of 2020 with the epidemic under control, although the online teaching mode fully demonstrated some advantages that offline teaching could not meet in the past, it also reflected some matters of online classroom and the necessity of offline classroom. This makes the online and offline blending teaching mode integrating the two modes recognized, explored and practiced by many colleges and universities. Taking the course "Introduction to earth science" as an example, this paper summarizes the previous offline and online

*Corresponding Author:

Xiehui Li,

School of Atmospheric Sciences, Chengdu University of Information Technology, Chengdu, Sichuan, 610225, China;

Email: lixiehui325328@163.com 
teaching modes, and explores the construction of online and offline blending teaching mode of the course in our university in the post epidemic era, in order to improve the comprehensive teaching effect and provide reference for the similar situations.

\section{Overview and Objectives of the Course}

The course "Introduction to earth science" is the foundation for comprehensively understanding several subjects including the basic principles of coordinated development of human and environment, synthetic geology, geography, geophysics, atmospheric science, oceanography, environmental science, and ecology. It is not only a basic general course integrating science and interest but also a public elective course for the cultivation of college students' scientific quality. The study of this course can enable students majoring in natural science, engineering science, humanities and social sciences to establish a scientific view of nature, dialectics and sustainable development. The course is a professional elective course for students majoring in Atmospheric Science and Applied Meteorology in the School of Atmospheric Sciences, Chengdu University of Information Technology. At present, the course is planned to be offered in the second semester, with a total of 24 theoretical class hours. Daily performance accounts for $20 \%$ of the course assessment results and final examination accounts for $80 \%$. The textbook is the Introduction to Earth Science, a Curriculum Textbook for 21st Century, edited by Benpei Liu and Yunlong Cai published by Higher Education Press. The main contents of the course include the basic astronomical knowledge of the planet earth, the layer surrounding the earth (atmosphere), the structure and function of the earth surface system (including stratosphere, geomorphology, hydrosphere, soil sphere, biosphere, etc.), and the earth environment and resources as the basis of human development. The textbook strictly emphasizes the universality of the content and tries to comprehensively introduce the relevant knowledge of the whole earth system, especially the relationship and overall role of various elements ${ }^{[2]}$.

Before the epidemic, this course mainly adopted the traditional teacher-centered teaching method. Scheduled to start in the second semester of freshman year, the course is the first professional course for students, who are relatively enthusiastic and have high expectations. As the high-quality course of our university, although it is an elective course, almost all students take it every year. The total number of students in the last two years has reached 760. The course is expected to make students grasp some realistic principles and methods, discuss the past based on the present, and discuss the present and the future based on the past on the basis of understanding relevant knowledge. In combination with their majors, students should clarify the position of the atmosphere in earth science and its relationship with other spheres, establish individual and overall, micro and macro dialectical thinking, inspire students to take the initiative in research and exploration, encourage innovation, enhance their interest in learning atmospheric science, cultivate students' materialistic view of nature and cosmology and promote the harmonious development of human and the earth. The course is expected to provide necessary background knowledge for subsequent professional courses by expanding students' knowledge vision and overall concept. Therefore, as the foundation to guide students into the palace of atmospheric science, the course is relatively important in the college education.

\section{Exploration on the Construction of Online and Offline Blending Teaching Mode}

Traditional offline teaching mode often has the following problems: teachers play the leading roles in class; students lack initiative in learning; various teaching methods are need; teaching evaluation methods are simple, etc. Instead, online teaching mode can make up for it with the characteristics that students are not limited by time and space; autonomous learning environment can be established; more interaction opportunities in classroom are available; classroom resources and evaluation methods are richer, etc. The online and offline blending teaching mode combining the two modes is more multidimensional, diverse, flexible and practical. At present, the commonly used online teaching modes can be summarized as synchronous and asynchronous online teaching mode, online flipped classroom teaching mode, accurate teaching mode based on learning situation analysis tools, theme exploration teaching mode based on learning resources website, autonomous learning mode based on subject tools and interactive teaching mode based on Internet. Various online teaching modes have their own advantages and disadvantages. When selecting, students need to combine the characteristics of the courses, the school environment and their own situation. Students can adopt one of the modes, or blending teaching modes through numerous attempts, summarize and practice the appropriate teaching mode, so as to achieve the mutual satisfaction of teachers and students and obtain a great teaching effect ${ }^{[3]}$.

\subsection{Online-only Teaching Mode during the Epidemic}

In the early spring of 2020 , influenced by the COVID-19, the course "Introduction to earth science" 
mainly adopts the online-only teaching mode, and the textbook is the electronic materials corresponding to the paper version. Considering the network environment and the continuity of teaching, the online-only teaching mode is realized by adopting the recording of course video $+\mathrm{MOOC}+\mathrm{SPOC}+$ online resources of high-quality open course + QQ group + Tencent meeting. The whole teaching procedures are as follows: (1) Before class, the teacher shall record the short video of each lesson (2030 mins), and select the open course online resources corresponding to the teaching content from MOOC, SPOC and high-quality open course. Online course resources are relatively rich because there are many colleges and universities offering the course. However, these online resources come from different majors, curriculum and textbooks, so the contents of each chapter and emphases are different. In order to correspond to, complement and add zest to our course, the course taught by Yilai Zhao in Guilin university of technology on MOOC, the course taught by Qingzhong Chu in Yanshan University on SPOC and the sharing course taught by Danping Yan in China University of Geosciences on high-quality open courses platform are selected. Teachers will send these learning resources and courseware to students through QQ groups in advance to facilitate them to prepare lessons before class. (2) In the class, teachers first set up multiplechoice questions to answer, which can reflect not only the attendance rate of students, but also their learning performances, letting students who have not finished learning can continue to study. Generally, students' problems encountered in learning are mainly answered through QQ groups. There are three classes learning this course, with the number of about 130 . During the 24 classes, students actively exchange various questions in QQ groups, and all students can participate in. Besides answering students' important and difficult problems, this method also expands knowledge region, improves students' learning interest and participation enthusiasm, and broadens their mind, receiving better learning effect and students' recognition. (3) After class, students can consolidate and deepen the understanding of the course and further expand their knowledge through homework assigned in QQ groups. In addition, teachers will introduce the course content in the first class, consolidate the key and difficult points in the middle of the course, and summarize and answer questions in the last class by broadcasting in Tencent classroom.

\subsection{Construction of Online and Offline Blending Teaching Mode in Post-epidemic Period}

Given the disadvantages of traditional offline teaching mode including students' low interest and participation in learning, inefficiency, inadequate attention, and monotonous classroom teaching and evaluation, and the advantages of pure online teaching during the epidemic period, the online and offline blending teaching mode is constructed under the background of "Internet plus education". By introducing the recording of course video $+\mathrm{MOOC}+\mathrm{SPOC}+$ online resources of high-quality open courses + Flipped Classroom + Rain Classroom + QQ group + WeChat + Tencent meeting, the online and offline blending teaching mode provides services for students' self-study before class and auxiliary learning in class by integrating various teaching resources in the learning process, realizing the teaching design idea of "online self-study before class, offline discussion in class, and consolidation and extension after class". The whole teaching procedures are as follows: (1) Before class (online self-study): Teachers upload micro-lectures (recorded course videos) and teaching resources such as MOOC, SPOC, quality open courses, courseware, key and difficult contents previously selected for online-only teaching to QQ groups. Students download course materials and learn in advance through computers, iPads, mobile phones and other mobile devices. In the process of pre-class learning, students can interact with teachers and other students through QQ and WeChat at any time, and summarize the important, difficult and doubtful problems they encounter. (2) In class (offline discussion): With the help of the intelligent teaching tool "rain classroom", teachers first pose questions for students to answer, learn about the results of students' online self-study, then explain the knowledge in detail, and solve the difficult questions encountered and put forward before. In this process, according to the students' learning status, some important and difficult problems can be discussed in group. (3) After class (consolidation and extension): Teachers assign homework in QQ group and upload learning resources related to knowledge learned in class. With the help of QQ, WeChat and other learning groups, students and teachers can put forward questions about their homework and get answers at any time. Through the communication and discussion, the learned knowledge in class can be consolidated and expanded ${ }^{[4]}$. During this process, the common problems can also be exchanged, solved and discussed in real time through Tencent meetings.

\section{Conclusions}

Blending teaching is an open and pluralistic educational practice, which is not a simple superposition of traditional classroom and online learning, but an integration of diversified teaching modes and different teaching objects, 
teaching contents and teaching needs ${ }^{[5]}$. In the new era of Internet plus education, online and offline blending teaching mode is suitable for the new demand of online teaching resources development represented by MOOC and the new requirements of undergraduate teaching reform in colleges and universities. The blending teaching mode will become the new normal in the post epidemic era, and is also an inevitable trend of future development. Based on the offline and online teaching practice of the course "Introduction to earth science" and the actual situation and curriculum objectives of the University, conforming to the trend of teaching reform, this paper puts forward the idea of blending teaching mode combining the advantages of the two teaching modes, applies it to the following practical teaching, in order to improve the teaching quality and achieve the ultimate goal of education.

\section{Funding}

This paper is funded by undergraduate teaching engineering project of Chengdu University of Information Technology " Introduction to Earth Sciences" online and offline blending curriculum construction project (BKJX2020020).

\section{References}

[1] Jinling Yang, Xiange Cao, Xiaying Wang. Innovation of "online + offline" blend-teaching mode in post epidemic era--from the perspective of Surveying and Mapping Courses[J]. Mapping Engineering, 2021, 30(01): 71-75.

[2] Benpei Liu, Yunlong Cai. Introduction to Earth Science[M]. Higher Education Press, 2019.

[3] Miao Wang. Reflection and improvement of online and offline mixed teaching mode of Basis for C\#Programming $[\mathrm{J}]$. Computer and Information Technology, 2021, 29(02): 88-91.

[4] Xiehui Li, Lei Wang. Thinking on the Mixed Teaching Mode of Introduction to Earth Science under the Background of "Internet + Education" [J]. Research on Innovative Education, 2019, 7(6): 715-718.

[5] Wei Bao, Dechun Chen, Jing Wang. Research on online and offline learning paradigm and teaching effectiveness in the post epidemic era -- a comparative analysis based on the survey data of online and offline College Students[J]. China Educational Technology, 2021(06): 7-14. 